\title{
Automated satellite-based estimation of crop water requirement for irrigated horticultural industries in northern Victoria
}

\author{
$\underline{\text { A.L. Weeks }}^{\mathrm{a}}$, C. Beverly ${ }^{\mathrm{a}}$, D. Whitfield ${ }^{\mathrm{b}}$, M. Abuzar ${ }^{\mathrm{c}}$ and J. McInnes ${ }^{\mathrm{a}}$ \\ ${ }^{a}$ Department of Economic Development Jobs Transport and Research, Rutherglen ${ }^{a}$, Tatura $^{b}$ \& Parkville \\ Victoria, Australia \\ Email:anna.weeks@ecodev.vic.gov.au
}

\begin{abstract}
The horticultural industry in Victoria is currently experiencing significant structural pressures due to a range of issues, including water constraints through the introduction of Sustainable Diversion Limits (SDL's), access to productive land and infrastructure, climate change and competition with overseas imports. Bio-economic models such as the Victorian Water Policy Model enable policy makers to explore scenarios which aim to optimize agricultural productivity and the trade-offs between various agricultural industries and regions under a series of water availability and physical constraints. However, the current data-sets which populate these models such as land-use, irrigation demand and production estimates are often sparse and not frequently updated. This paper discusses the design and implementation of an automated process to provide enhanced estimates of irrigated water use across the horticultural industries of northern Victoria. The service derives regional crop coefficient relationships for the horticultural industries using SEBAL-METRIC estimates of Evapotranspiration, Penman-Monteith estimates of potential evaporation and calculated Normalized Difference Vegetation Index (NDVI) from the Landsat-8 satellite. Application of the crop coefficient relationships provides estimates of crop evapotranspiration rates and irrigation water use over time. Automated reports for each horticultural industry within the water-trading-zones of the northern Victoria irrigation districts provide information on the distribution of crop coefficient curves, irrigation area, estimated evapotranspiration and water application. This information is critical for water resource management and to support physically-based biophysical models. It is anticipated that over time the service will also provide information on land-use transition and the adaptation of irrigation practices to changes in water availability.
\end{abstract}

Keywords: $\quad$ Irrigation, Landsat-8, crop water requirement, NDVI, horticulture 
Weeks et al., Automated satellite-based estimation of crop water requirement for irrigated horticultural industries in northern Victoria

\section{INTRODUCTION}

In an environment of uncertain climate and water allocations there is a need to better understand the impacts of water policy on production and profitability so that governments can more strategically invest in irrigation infrastructure and expansion into new markets. Bio-economic models such as the Victorian Water Policy Model (DPI, 2009) enable policy makers to assess regional impacts of specific policies, such as the implementation of Sustainable Diversion Limits (SDL's), however they have historically relied on static ABS census data, industry surveys and generic crop water use estimates. These datasets are often expensive to obtain, quickly become outof date, are industry specific, have limited domains and generally only have yield and profit data for a small number of representative sites. This paper describes an approach to capture some of the recent developments in satellite evaluation methods by routinely producing satellite-based derivatives to provide enhanced datasets to underpin bio-economic models.

An application, SciSAT, has been developed to automatically capture and process satellite data to provide timely, reproducible, cloud-free estimates of Normalized Difference Vegetation Index (NDVI). With an immediate focus on irrigated horticulture across northern Victoria, the NDVI estimates have been used to infer key attributes including irrigation area, crop coefficients and crop water requirement, with future plans to estimate crop-type, phenology, biomass and yield based on work by O'Connell (2011). In an approach similar to Hellegers et al. (2008), estimates of 'crop water productivity' (Yield/ET) will ultimately be used to populate an enhanced Victorian Water Policy Model (in prep.) and to estimate the 'economic water productivity' across the different irrigation regions and industries.

Satellite approaches to estimating crop water requirement based on SEBAL-METRIC calculations of

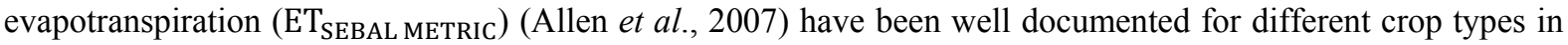
the Victorian irrigation regions (O'Connell, 2011; Abuzar et al., 2012; Whitfield et al., 2010; Whitfield et al., 2012). Tasumi et al. (2005) demonstrated that crop coefficients $\left(K_{c}\right)$, or the ratio of ET SEBAL METRIC to a reference potential evapotranspiration could be well described by a linear function of NDVI for a number of irrigated crops including alfalfa, legumes and cereals. In an extension to this Whitfield et al. (2012) demonstrated that a similar approach could be applied to horticultural crops, however the reference 'short-crop' potential evaporation was adapted to a 'tall-crop' potential evapotranspiration and the generic crop coefficient relationship modified. This paper uses the $K_{c}$ relationship derived by Whitfield et al. (2012) for almonds. Future work will involve the calculation of the SEBAL-METRIC evapotranspiration in SciSAT to confirm the crop coefficient relationships for the varied crop-types within northern Victoria's horticultural industries.

The following paper presents an overview of the software development of SciSAT and a case-study which includes the calculation of key irrigation attributes for an almond-growing area in the Lake Powell irrigation district of northern Victoria.

\section{METHODS}

\subsection{Software development}

The software application SciSAT was developed to automatically capture and process satellite data to a format that would enable rapid filtering and statistical analysis through both spatial and temporal dimensions. Key design considerations included the full automation of data processing, reproducible methodology, retention of metadata, amalgamation with other key datasets and broad departmental access to datasets, toolkits and source code. Currently the application runs for the Landsat-8 satellite (USGS, 2015), incorporating data from mid2013 (when the satellite became operational) to present. The domain spans the State of Victoria, capturing data from over twenty Landsat-8 'scenes' at a 30m resolution every sixteen days with storage requirements of approximately 1 TB per year.

SciSAT runs as a scheduled task on a high-end computational and data-processing environment SciKIT, (Victorian Department of Economic Development) with the processed satellite data stored in a shared 'reference' data-space. Users can map to the data and interrogate it using the SciSAT Viewer application. The main software development has been compiled in MATLAB (http://au.mathworks.com/), making use of the built-in image processing tools.

\section{The six major tasks of the process are outlined in}

Figure 1 and described in detail below. Tasks 2 to 5 run as a scheduled task on a daily basis. 
Weeks et al., Automated satellite-based estimation of crop water requirement for irrigated horticultural industries in northern Victoria
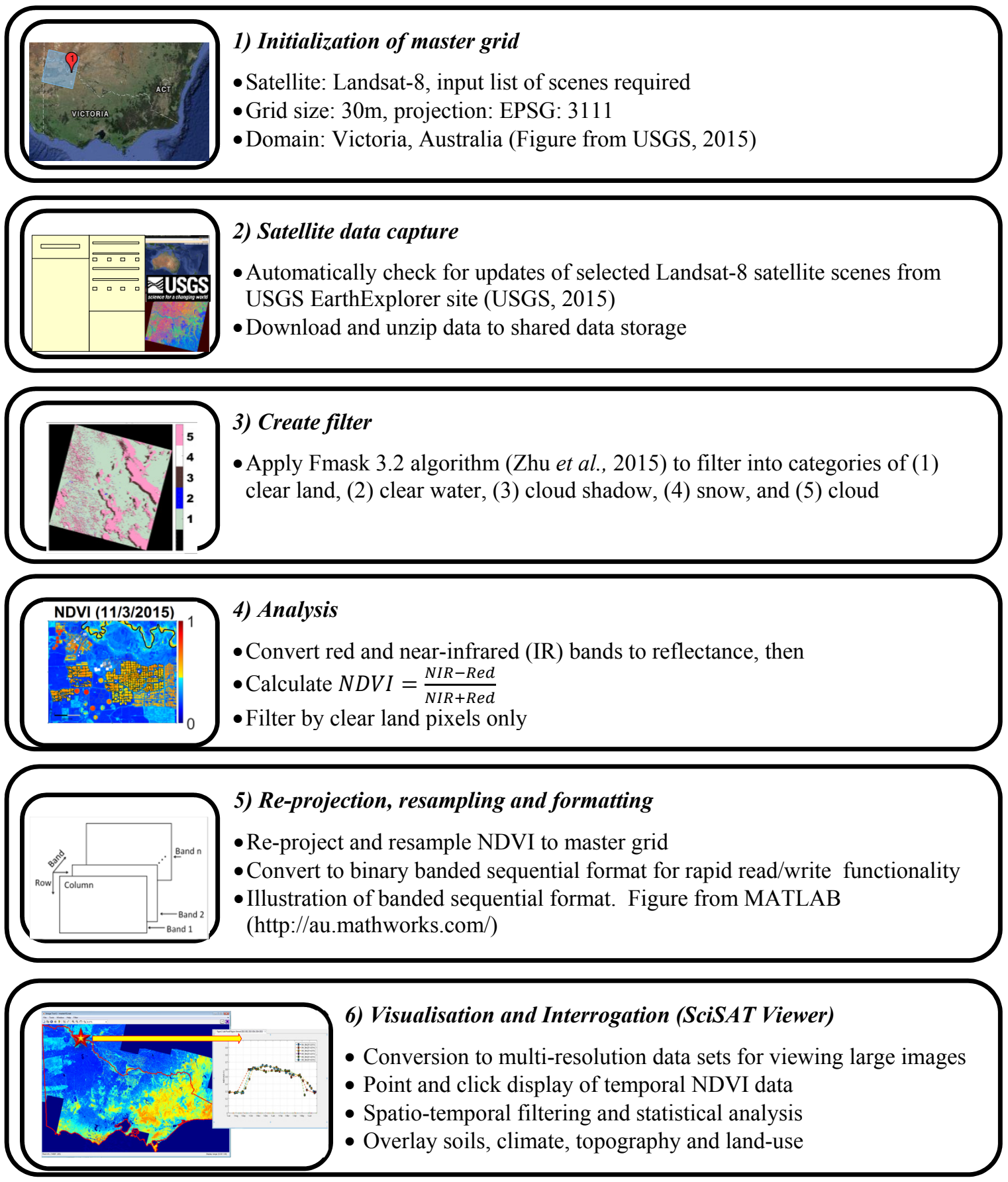

Figure 1. Major tasks of SciSAT application.

\section{Initialization of master grid}

Key inputs required to initialize the application include satellite ID, scene list, and the domain, projection and grid size of the master grid to which all satellite data is resampled. The application is generic and could be applied across different domains for a number of satellite feeds.

\section{Satellite data capture}

The Landsat-8 data is downloaded via the USGS EarthExplorer site (USGS, 2015) using a modified version of the open-source python script download_landsat_scene.py (Hagolle, 2015). The script logs into the USGS site then reads a customized URL string based on a scene path, row and date. Once downloaded, the files are 
Weeks et al., Automated satellite-based estimation of crop water requirement for irrigated horticultural industries in northern Victoria

unzipped creating a folder containing one QA file, one metadata file and 11 bands of Landsat-8 data stored in georeferenced tagged-image-file (tif) format.

\section{Create filter}

The Fmask 3.2 algorithm (Zhu et al., 2015) is applied to each scene as it is downloaded, creating a mask to filter the scene into categories of clear land, clear water, cloud, cloud shadow, snow and no-observation.

\section{Analysis}

Prior to calculating the NDVI, the red (band 4:655nm) and near-infra-red bands (band 5: 865nm) are converted to Top Of Atmosphere (TOA) reflectance values with a correction for sun angle, using the standard conversion outlined in USGS (2015). The vegetation index (NDVI) is calculated as the ratio of these bands then filtered so that only 'clear-land' pixels are represented.

\section{Re-projection, resampling and formatting}

The NDVI data is then re-projected and resampled onto the master grid using the open-source Geospatial Data Abstraction Library software (GDAL, 2015). This aligns successive scenes onto a common mesh and alleviates problems that arise from small offsets in the satellite position over time and satellite data that spans multiple projections. The final step converts the NDVI from its original georeferenced tif format to a binary bandedsequential (BSQ) format. This format enables data to be rapidly extracted through the space-time dimensions by utilizing the built in multi-band read/write functionality of MATLAB. Each scene is stored in an individual BSQ file with successive timestamps appended to the file as an additional band. A translation matrix for each scene enables direct mapping of the BSQ file to the master grid for visual interpretation.

\section{Visualization and interrogation (SciSAT Viewer)}

The satellite data is visualized and interrogated through the SciSAT Viewer, an executable run on a local machine mapped to the data repository on the SciKIT server. Functionality includes conversion to multiresolution data sets for large image viewing, point and click temporal display of NDVI data, amalgamation of soils, topography, climate and land-use datasets, spatio-temporal filtering and statistical analysis by shapefile polygon, and estimates of irrigation area, crop coefficients, growing season and crop water requirement as detailed below.

\subsection{Crop water requirement}

Pixel-scale estimates of crop coefficient $\left(K_{c}\right)$, or, the ratio of $E T_{\text {SEBAL METRIC }}$ to a reference 'tall-crop' potential evapotranspiration (Allen et al., 2007) were calculated using the almond relationship derived by Whitfield et al. (2012) using the satellite-based Normalized Difference Vegetation Index (NDVI)

$$
K c=\frac{E T_{\text {SEBALMETRIC }}}{E T_{\mathrm{r}}}=f(N D V I)=1.3(N D V I-0.1)+0.22
$$

$N D V I$ and $K_{c}$ were then downscaled to daily interpolation curves $\left(\widetilde{N D V I}, \widetilde{K_{c}}\right)$ for the calculation of daily evapotranspiration and crop water requirement. The program SPLINEFIT (Lundgren, 2014) was used to create a cubic-spline interpolation of the data using a method of least-squares to remove the influence of outliers such as NDVI data confounded by cloud. Crop water requirement (CWR), defined as the minimum water required to maintain crop growth in stress-free conditions was calculated as

$$
C W R=\sum_{t=a}^{b} \operatorname{ET}(t)-R(t), \quad E T(t)=\widetilde{K_{c}}(t) E T_{r}(t)
$$

where $E T(t)$ was the calculated evapotranspiration, $R(t)$ the daily rainfall sourced from spatially referenced SILO Datadrill meteorological data (SILO, https://www.longpaddock.qld.gov.au/silo) and $E T_{r}(t)$ the reference 'tall-crop' potential evapotranspiration calculated from the SILO data using methods described in Allen et al., (2007). CWR was summed over the irrigated growing season $(a \leq t \leq b)$, defined by $\widehat{N D V I}(t)>0.45$. This value was based on both experimental and theoretical studies showing that vegetation requires an NDVI of greater than 0.4 to absorb a significant proportion of incident radiation (e.g. Nemani and Running, 1997). It was observed that across northern Victoria the dry summers and water-limiting environment meant that generally, only well watered crops could achieve such NDVI values. Following on from this, the example below demonstrates that broad calculation of $C W R$ across northern Victoria could also be used effectively as a surrogate to estimate irrigation area. 
Weeks et al., Automated satellite-based estimation of crop water requirement for irrigated horticultural industries in northern Victoria

\section{CASE STUDY}

The following case study presents the application of SciSAT to estimate irrigation area, crop coefficients, growing season and crop water requirement for an almond growing area in the Lake Powell irrigation district. Detailed horticultural land-use information for the 2013-2014 irrigation season was sourced from SunRISE (http://www.sunrise21.org.au/) and used to classify irrigation areas and to provide information of horticultural crop type. Figure 2 demonstrates the steps undertaken to calculate the CWR for a single pixel with CWR for a given season (July $\mathrm{Y}_{\mathrm{Y}-1} \rightarrow$ June $_{\mathrm{Y}}$ ) defined as the cumulative ET minus the cumulative rainfall for the irrigation growing season within that year.

CWR was calculated for all pixels in the Lake Powell irrigation district with results presented in Figure 3. The Lake Powell almond growing area covers approximately 3793 ha and is represented in Figure 3(a) by the polygons outlined in black. Figure 3(b) shows the change in the distribution of interpolated crop coefficients over time, with a median value in the summer months of approximately 0.85 , dropping below 0.5 over winter. Figure 3(c) shows the full distribution of crop water requirement over the almond-growing area which ranged between 4.0 and $17.3 \mathrm{ML} /$ ha with a median value of $13.8 \mathrm{ML} / \mathrm{ha}$.

(a)

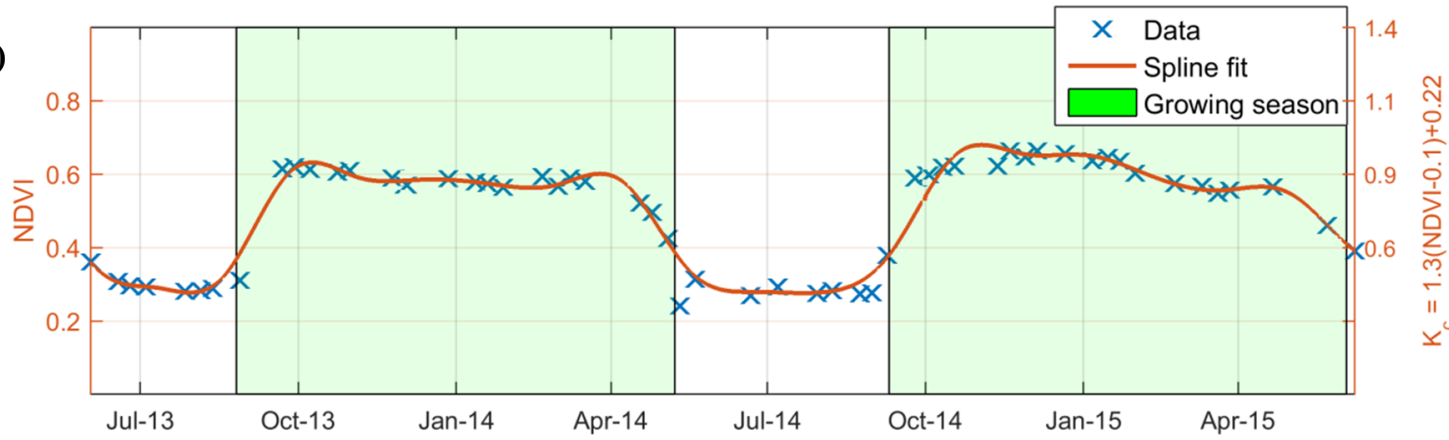

(b)
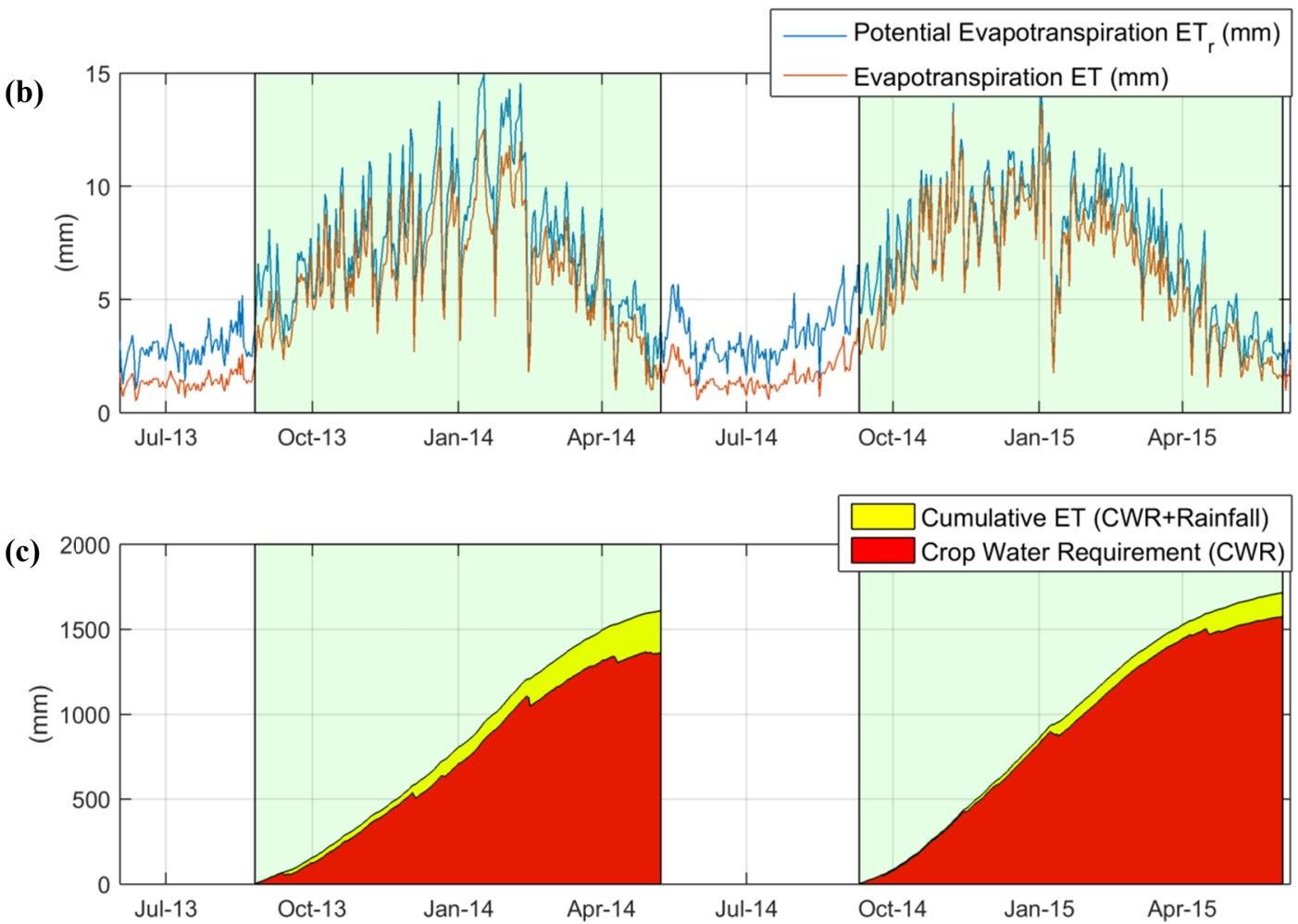

Figure 2. Calculation of crop water requirement for a single pixel in an almond-growing area. Figure 2(a) shows the Landsat-8 NDVI satellite data represented by blue crosses, captured using the SciSAT application from mid-2013 to present. The right hand axis shows the equivalent $\boldsymbol{K}_{\boldsymbol{c}}$ value. The solid red line depicts the cubic spline interpolation of the satellite data. The shaded area in green defines the irrigation growing season over which the crop water requirement is accumulated. Figure 2(b) shows the potential evapotranspiration, $\boldsymbol{E} \boldsymbol{T}_{\boldsymbol{r}}$, and the actual evaporation, $E T$, calculated using the interpolated crop coefficient $\widetilde{\boldsymbol{K}_{\boldsymbol{c}}}$. Figure 2(c) shows the cumulative $E T$, partitioned by rainfall and irrigated crop water requirement. 
Weeks et al., Automated satellite-based estimation of crop water requirement for irrigated horticultural industries in northern Victoria

\section{DISCUSSION}

The development of SciSAT has dramatically reduced the processing time for satellite based applications with daily updates and automated processing of the satellite imagery meaning that near real-time analysis can be conducted across Victoria with processed results feeding directly into biophysical and bio-economic models. The design focus of aligning datasets to a common mesh allows for rapid splicing and analysis of data across temporal and spatial dimensions. To demonstrate the utility of SciSAT this paper has presented an example of the calculation of crop water requirement for the almond growing area of the Lake Powell Irrigation District. Recognizing that work still remains to re-derive the crop coefficient relationships used in this study, the median estimates of 2013-2014 crop water requirement (13.8 ML/ha) were well within the reported almond irrigation benchmarking based on growers' information from 53 Victorian sites in which the benchmark median value ranged between 9.7 ML/ha and $15 \mathrm{ML} / \mathrm{ha}$ for 2003 and 2011(DPI, 2012). Calculations of crop water requirement, previously based on a single snapshot of NDVI during the peak of the irrigation season, have been enhanced by utilizing the temporal component of the data and estimating the length of growing season. The distribution of the interpolated crop coefficient curves presented in Figure 3(b) provide information on the crop phenology and the variability over space and time that previously could only be obtained from field trial or survey data. The crop coefficient distributions will be used to inform biophysical horticultural models that presently rely on generic curves and do not account for any variability over space or time. Other applications include the broad-scale estimation of irrigation area as illustrated in Figure 3(a) where a threshold of CWR $<4$ $\mathrm{ML} / \mathrm{ha}$ (greyed out region) has been used to delineate areas of irrigation from dryland areas. On-going work includes (1) calibrating/validating the Kc-NDVI relationships across the varied horticultural industries through the implementation of the SEBAL-METRIC algorithm into SciSAT, (2) cross-checking the CWR estimates to recorded irrigation supply data, and (3) establishing relationships between NDVI and crop yield based on the approach outlined in O'Connell (2011).

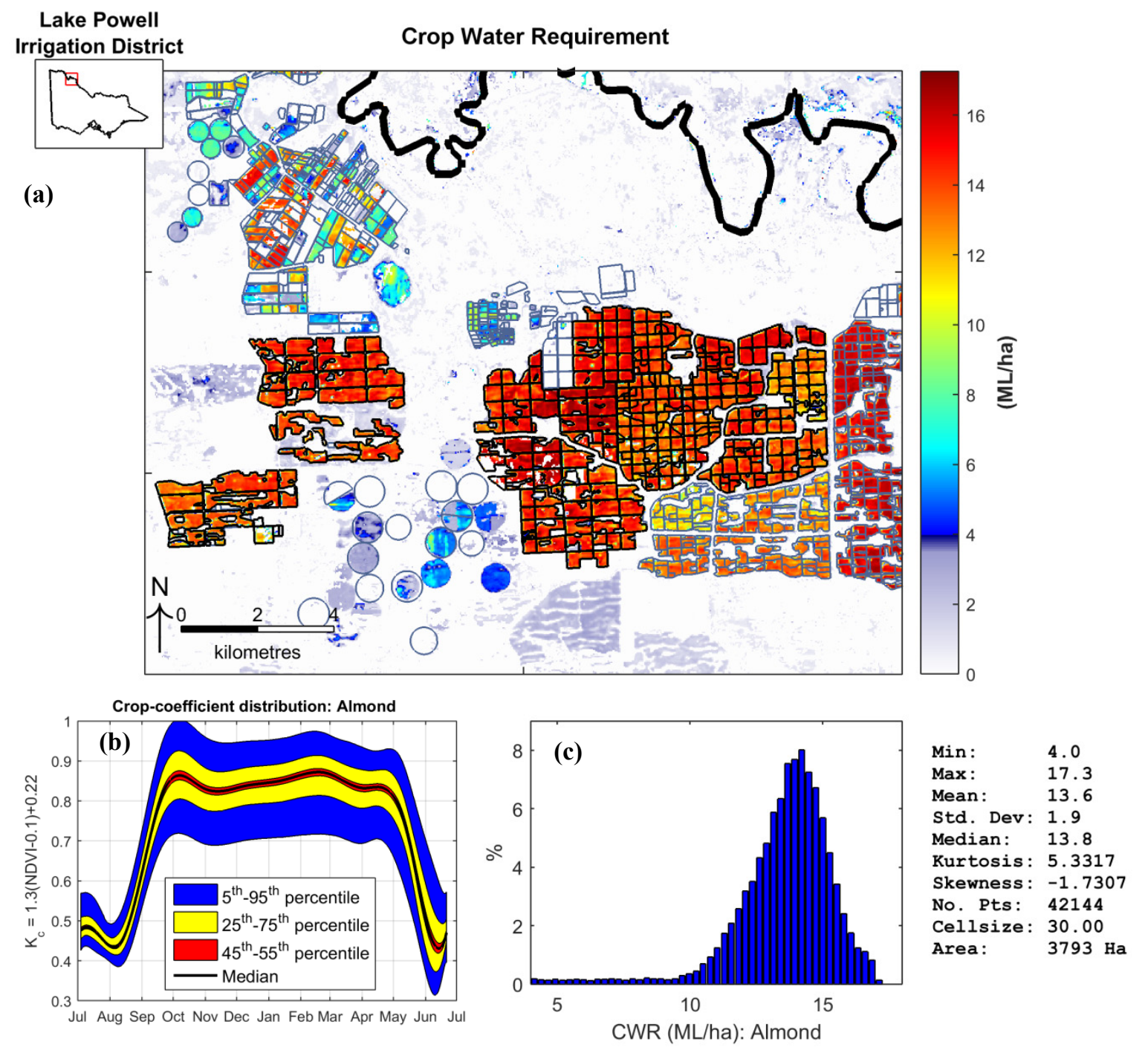


Weeks et al., Automated satellite-based estimation of crop water requirement for irrigated horticultural industries in northern Victoria

Figure 3. 2013-2014 Irrigation season Lake Powell Irrigation District. Figure 3(a) presents spatial CWR (ML/ha) with Lake Powell almond-growing areas represented by polygons outlined in black. Grey polygons represent other landuses and/or irrigation districts as defined by the SunRISE landuse data. Figure 3(b) shows the distribution of the interpolated crop coefficients for all pixels in the almond-growing areas as a function of time with Figure 3(c) showing the corresponding distribution of CWR.

\section{CONCLUSIONS}

Whilst there has been significant development of satellite-based methodologies to estimate key irrigation attributes, limited automated tools are available to routinely update the types of models used by government to make decisions on water policy. The development of SciSAT to automatically capture and process satellite data to a form that enables rapid spatial and temporal rapid filtering and statistical analysis provides a powerful tool that can readily estimate up-to-date information on irrigation areas, crop coefficients and crop water requirement, with future potential to deliver crop biomass and yield. The Lake Powell irrigation district application demonstrated the ability of the framework to derive distributions of crop coefficient curves over time and produced median crop water requirements that were comparable to benchmarking studies.

\section{REFERENCES}

Abuzar, M., McAllister A., Whitfield, D., and K. Sheffield (2012). Remote Sensing Analysis of Crop Water Use in the Macalister Irrigation District. Proceedings of the Geospatial Science Research 2 Symposium, Melbourne, Australia, December 10-12, 2012. ISBN: 978-0-9872527-1-5

Allen, R.G., Pereira, L.S., Raes, D., and M. Smith (1998). Crop evapotranspiration: Guidelines for computing crop water requirements, FAO Irrigation and Drainage Paper 56, FAO, Rome.

DPI (2009). Vic DPI Water Policy Model (WPM). Model Documentation. Department of Primary Industries, Melbourne.

DPI (2012). Almond Irrigation Benchmarking 2002-2011. Horticulture Services. Department of Primary Industries. ISBN 978-1-74326-153-8.

GDAL (2015). Geospatial data Abstraction Library, http://www.gdal.org/. Accessed 11 June 2015.

Hagolle O. Landsat-download (open source code). Automated download of LANDSAT data from USGS website, http://olivierhagolle.github.io/LANDSAT-Download, Accessed 11 June 2015.

Hellegers, P., Soppe, R., Perry, C., and W. Bastiaanssen (2008). Combining remote sensing and economic analysis to support decisions that affect water productivity. Irrigation Science, 27, 243-251. DOI 10.1007/s00271-008-0139-7.

Lundgren, J. (2014). SPLINEFIT (open source code): Accessed 11 June 2015 http://au.mathworks.com/matlabcentral/fileexchange/13812-splinefit

Nemani, R., and S. Running (1997). Land Cover Characterization using multi-temporal RED, NEAR-IR and Thermal-IR data from NOAA/AVHRR. Ecological Applications, 7, 79-90. http://dx.doi.org/10.1890/10510761(1997)007[0079:LCCUMR]2.0.CO;2

O'Connell, M. (2011). Satellite Based Yield - Water Use Relationships of Perennial Horticultural Crops. A thesis submitted in total fulfilment of the requirements of the degree of Doctor of Philosophy. Department of Agriculture and Food Systems, Melbourne School of Land and Environment, The University of Melbourne, Victoria, Australia.

Tasumi, M., Allen, R.G., Trezza, R., and J.L. Wright (2005). Satellite-Based Energy Balance to assess withinpopulation variance of crop coefficient curves, Journal of Irrigation and Drainage Engineering ASCE, 131, 94-109.

USGS (2015). Earth Explorer: http://earthexplorer.usgs.gov/. Using the USGS Landsat 8 Product http://landsat.usgs.gov/Landsat8_Using_Product.php. Data available from the U.S. Geological Survey.

Whitfield, D., McAllister, A., Ābuzar, M., Sheffield, K., O'Connell M., and L. McClymont (2010). Measurement, monitoring and reporting systems for improved management of farm and regional water resources in Australia: Final Report. Department of Primary Industries, State of Victoria.

Whitfield, D., O'Connell, M., McAllister, A., McClymont, L., Abuzar, M., and Sheffield, K. (2012). SEBALMETRIC estimates of crop water requirement in horticultural crops grown in SE Australia, Acta Horticulturae, 922, 141-148.

Zhu, Z., Wang, S. and C.E. Woodcock (2015). Improvement and expansion of the Fmask algorithm: cloud, cloud shadow, and snow detection for Landsats 4-7, 8, and Sentinel 2 images. Remote Sensing of Environment, 159, 269-277. ISSN 0034-4257, http://dx.doi.org/10.1016/j.rse.2014.12.014. 